\title{
ADUBAÇÃO FOSFATADA MINERAL E ORGANOMINERAL NO DESENVOLVIMENTO DO MILHO
} Carlos Sérgio Tiritan
Júnior
${ }^{(4)}$

(1) Professor Doutor da Faculdade de Agronomia, Universidade do Oeste Paulista - UNOESTE. Rodovia Raposo Tavares, km 572, CEP 19067-175, Presidente Prudente-SP. tiritan@unoeste.br; (2) Doutorando em Agricultura, Faculdade de Ciências Agronômicas - Unesp. Fazenda Lageado, Botucatu-SP. diego@fca.unesp.br; ${ }^{(3)}$ Pesquisador Científico da Empresa Brasileira de Pesquisa Agropecuária Embrapa Soja. Rodovia Carlos João Strass, s/n, CP 231, CEP 86001-970, Londrina-PR. (4) Discente da Faculdade de Agronomia, Universidade do Oeste Paulista - UNOESTE. Rodovia Raposo Tavares, km 572, CEP 19067-175, Presidente Prudente-SP.

\section{RESUMO}

O objetivo deste trabalho foi avaliar os efeitos do fósforo na cultura do milho submetido à adubação fosfatada mineral e organomineral. O experimento foi conduzido no viveiro de mudas da Universidade do Oeste Paulista. $O$ delineamento experimental foi em blocos inteiramente casualizados, com 8 tratamentos e 4 repetições, sendo quatro doses de fósforo $\left(0,30,60\right.$ e $\left.120 \mathrm{Kg}_{\text {de }} \mathrm{P}_{2} \mathrm{O}_{5} \mathrm{ha}^{-1}\right)$ na ausência e presença de $300 \mathrm{~kg} \mathrm{ha}^{-1}$ do adubo orgânico. Aos 45 dias após a emergência efetuou-se o corte para determinação da matéria seca, do teor de fósforo na parte aérea da planta, e do acúmulo de fósforo na fitomassa seca. $O$ adubo orgânico possibilita redução das doses de fósforo no desenvolvimento da cultura do milho e eleva o teor de fósforo acumulado na parte aérea, mesmo na aplicação de baixas doses do fertilizante mineral.

Palavras-chave: Zea mays, fósforo, matéria orgânica.

\section{PHOSPHORUS FERTILIZATION MINERAL AND ORGANOMINERAL ON CORN}

\section{ABSTRACT}

The objective of this work was to evaluate the effects of the phosphorus on corn culture, submitted to the mineral and organomineral fertilizer. The experiment, realized on the Universidade do Oeste Paulista, by using a randomized complete block design, with eight treatments and four repetitions, four phosphorus doses $\left(0,30,60\right.$ and $120 \mathrm{Kg}$ of $\mathrm{P}_{2} \mathrm{O}_{5}$ ha $\left.^{-1}\right)$ in the absence and presence of $300 \mathrm{~kg} \mathrm{ha}^{-1}$ of the organic fertilizer. 45 days after the emergency occurred the cut for determination of the dry matter, of the phosphorus tenor in the aerial part, and of the phosphorus accumulation in the dry matter. The organic fertilizer allowed a reduction in the phosphorus doses for the development of the culture of the corn and it elevated the tenor of accumulated phosphorus in the part aerial, same when of the application of low phosphorus doses.

Key words: Zea mays, phosphorus, organic matter. 


\section{INTRODUÇÃO}

Apesar do alto potencial produtivo da cultura do milho (Zea mays L.), evidenciado por elevadas produtividades, o que se observa na prática no Brasil é que sua produção é baixa e irregular, sendo um dos principais motivos a baixa fertilidade do solo. Esse fato não se deve apenas aos baixos níveis de nutrientes presentes nos solos, mas também ao uso inadequado de calagem e adubações.

Uma importante função da matéria orgânica do solo diz respeito ao fornecimento de nutrientes aos vegetais, principalmente em relação ao fósforo, elemento mais limitante no desenvolvimento da agricultura em solos altamente intemperizados de ambientes tropicais (TIESSEN; MOIR, 1993). Nesses solos, o componente orgânico representa parte considerável do conteúdo disponível de fósforo (GUERRA et al., 1996; TURNER et al., 2003), que contribui para a nutrição das plantas pela sua mineralização (SIQUEIRA; MOREIRA, 2001).

Segundo Garcia (2005), o fósforo desempenha funções estruturais, como armazenamento e funcionamento de energia, e participa ativamente das funções fotossintéticas. Para Lopes (1988), por promover um bom desenvolvimento do sistema radicular, o fósforo permite aumentar a eficiência das plantas no uso da água, gerando menores perdas e melhor absorção de outros nutrientes, fazendo com que a planta sofra menos nos períodos de deficiência hídrica.

Para Santos (2006), o fósforo é o nutriente de planta que tem merecido maior estudo no que diz respeito à fertilidade do solo $\mathrm{e}$ seu papel na agricultura e é considerado problema para os solos das regiões tropicais. Embora muito pouco lixiviado, o fósforo aplicado no solo sofre reações químicas com a fase mineral, resultando em formas pouco disponíveis as culturas. Kamprath (1977), citado por Santos
(2009) considera que a fixação do fósforo adicionado sob a forma de fertilizantes ocorre predominantemente por reações com compostos de ferro e alumínio. Meurer (2006), por sua vez, relata que o fósforo é um dos nutrientes que mais limitam a produtividade das culturas nos solos de carga variável, que predominam nas regiões tropicais e subtropicais, caso dos solos brasileiros.

No caso do milho, deficiência de fósforo nos estádios iniciais de desenvolvimento acarreta redução no índice de espiga, representado pelo número de espigas por unidade de área, e consequentemente, redução na produção final dos grãos (MENGEL; KIRKBY, 1987).

Wetzel et al. (1979) relatam que a deficiência de fósforo durante o ciclo da cultura provoca redução no tamanho e na qualidade fisiológica das sementes. A deficiência de fósforo também é problemática, pois pode reduzir a absorção de nitrogênio, como demonstrado em diversos trabalhos, entre eles Lee (1982), Schjorring (1996), Rufty et al. (1993) e Magalhães (1995). Este último demonstrou que a omissão de fósforo em solução nutritiva, por dois dias, reduziu a absorção de nitrato em $63 \%$. A partir do sexto dia de omissão de fósforo, a absorção de nitrato caiu para zero, mesmo na presença de doses adequadas na solução nutritiva.

De acordo com Miller (1974), a aplicação de fósforo juntamente com nitrogênio dobrou a absorção de fósforo inorgânico $(\mathrm{Pi})$ pelas raízes, enquanto que a aplicação de $\mathrm{Pi}$ separadamente do nitrogênio proporcionou uma taxa 1,5 vezes menor na absorção de fósforo pelas plantas de milho.

Sendo assim, o presente trabalho teve por objetivo avaliar o efeito da adubação mineral e organomineral na cultura do milho, avaliando a produção fitomassa seca, o teor e o acúmulo de $\mathrm{P}$ na parte aérea da cultura do milho em estágio vegetativo. 


\section{MATERIAL E MÉTODOS}

O experimento foi conduzido no viveiro de mudas da Universidade do Oeste Paulista, durante os meses de agosto a novembro de 2007. O solo foi caracterizado, segundo Embrapa (2006), como Argissolo Vermelho Amarelo arenoso, sendo utilizado $15 \mathrm{~kg}$ de terra para cada vaso. Foram coletadas amostras para caracterização de atributos químicos (RAIJ et al., 2001) com os seguintes resultados: $\mathrm{pH}\left(\mathrm{CaCl}_{2} 1\right.$ mol L ${ }^{-1}$ ) 5,2; $11 \mathrm{~g} \mathrm{dm}^{-3}$ de MO; $12 \mathrm{mg} \mathrm{dm}^{-3} \mathrm{de}$ $P_{\text {resina; }} 21$ mmolc $\mathrm{dm}^{-3}$ de H+Al; 3,4 mmolc $\mathrm{dm}^{-3} \mathrm{de}$

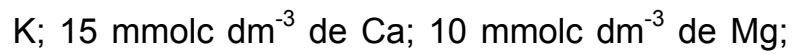

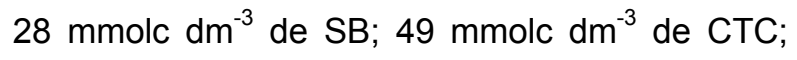
$58 \%$ de saturação por bases $(\mathrm{V})$.

A calagem foi efetuada 30 dias antes da semeadura do milho, procurando elevar a saturação por bases para $70 \%$. Utilizou-se um calcário dolomítico calcinado com PRNT de 100\% (32\% $\mathrm{CaO}$ e $18 \% \mathrm{MgO}$ ), na dose de 2,3 ton $\mathrm{ha}^{-1}$. Passado o período de incubação do calcário, o solo recebeu a adubação mínima de plantio, sendo $30 \mathrm{Kg} \mathrm{ha}^{-1}$ de $\mathrm{N}$ (uréia) e $50 \mathrm{Kg} \mathrm{ha}^{-1}$ de $\mathrm{K}_{2} \mathrm{O}$ (cloreto de potássio), segundo recomendações de Raij e Cantarella (1997), variando apenas as doses de fósforo segundo o delineamento experimental. Os tratamentos utilizados foram três doses de $\mathrm{P}_{2} \mathrm{O}_{5}$ e um tratamento controle $(0$, 30,60 e $120 \mathrm{Kg}$ de $\mathrm{P}_{2} \mathrm{O}_{5} \mathrm{ha}^{-1}$ ) na ausência e na presença de adubo orgânico (0 e $\left.300 \mathrm{~kg} \mathrm{ha}^{-1}\right)$. $\mathrm{O}$ delineamento experimental foi em blocos inteiramente casualizados, com 8 tratamentos e 4 repetições.

O adubo orgânico utilizado no experimento é um produto resultante do processo de compostagem de esterco de curral e esterco de galinha, misturado com palha de brachiaria e bagaço de cana.

A adubação foi realizada no sulco de plantio. Para calcular a dosagem exata de cada tratamento, considerou-se um espaçamento de $0,9 \mathrm{~m}$. Como os vasos utilizados possuíam $0,2 \mathrm{~m}$ de diâmetro, as dosagens foram as seguintes: 1,28; 2,57; e 5,13 gramas de superfosfato triplo, que correspondem, respectivamente, as doses de 30,60 e $120 \mathrm{~kg} \mathrm{ha}^{-1}$ de $\mathrm{P}_{2} \mathrm{O}_{5}$. Para os tratamentos organominerais, aplicou-se ainda 7,7 gramas do adubo orgânico, valor equivalente a $300 \mathrm{~kg} \mathrm{ha}^{-1}$, também no sulco de plantio.

A semeadura do milho (Híbrido Bayer Seeds) foi realizada utilizando-se cinco sementes por vaso. $O$ início da emergência das plântulas ocorreu cinco dias após a semeadura, e três dias após a emergência (DAE) realizou-se o desbaste, mantendo somente duas plantas por vaso. A umidade do solo foi mantida próxima à capacidade de campo do solo (180 g. $\mathrm{kg}^{-1}$ de água), através de regas diárias.

Aos 45 dias após emergência, com as plantas na fase de pleno florescimento, ou seja, no pico de acúmulo de matéria seca e máximo crescimento vegetativo, realizou-se o corte. Em seguida, as plantas foram enviadas ao Laboratório de Tecidos Vegetais da Universidade do Oeste Paulista. Em laboratório, as amostras foram submetidas à diagnose foliar para determinação do teor de fósforo na parte aérea da planta, utilizando o terço médio das folhas, segundo metodologia proposta por Raij et al. (1997). Em seguida as amostras foram secadas em estufa de aeração forçada a $60^{\circ} \mathrm{C}$, durante 72 horas, para a determinação da matéria seca.

Os dados foram submetidos à análise de variância. As médias referentes à adubação orgânica foram comparadas pelo de Tukey a $5 \%$ de probabilidade. Os efeitos das doses de fósforo foram avaliados por meio de análise de regressão, adotando-se como critério para escolha do modelo a magnitude dos coeficientes de regressão significativos ao nível de $5 \%$ de probabilidade pelo teste $t$. 


\section{RESULTADOS E DISCUSSÃO}

Os resultados de fitomassa seca das plantas de milho submetidas à adubação mineral e organomineral encontram-se na Figura 1. Notase que, na ausência do adubo orgânico, existe uma tendência positiva entre as variáveis correlacionadas, ou seja, à medida que as doses de $\mathrm{P}_{2} \mathrm{O}_{5}$ aumenta, aumenta-se também a fitomassa seca da parte aérea. Quando as mesmas doses de fósforo foram aplicadas na presença do adubo orgânico, a maior produção de fitomassa seca foi observada na dose de $30 \mathrm{~kg}$ ha $^{-1}$ de $\mathrm{P}_{2} \mathrm{O}_{5}$. Os resultados revelam, que ao aplicar fósforo associado com a adubação orgânica, na linha de plantio, as doses de adubo mineral fosfatado poderá ser reduzida. Este efeito está associado provavelmente a uma redução na fixação de fósforo pelos compostos minerais do solo, indicando que sistemas de manejo que promovem adição de matéria orgânica ao solo contribuem para elevar a disponibilidade do fósforo para as plantas, uma vez que carregadores orgânicos possuem a capacidade de melhorar a solubilidade dos compostos, disponibilizando mais rapidamente o fósforo, comparado com a sua aplicação sem a associação com fontes orgânicas.

Segundo Novais et al. (1980), o maior tempo de contato solo-fosfato, que causa sua maior solubilidade, causa também menos disponibilidade de fósforo para as plantas. No entanto, ao se aplicar um carregador orgânico associado a adubação fosfatada mineral, a matéria orgânica protege o fósforo, inibindo as reações de fixação do elemento com os óxidos de ferro e alumínio.

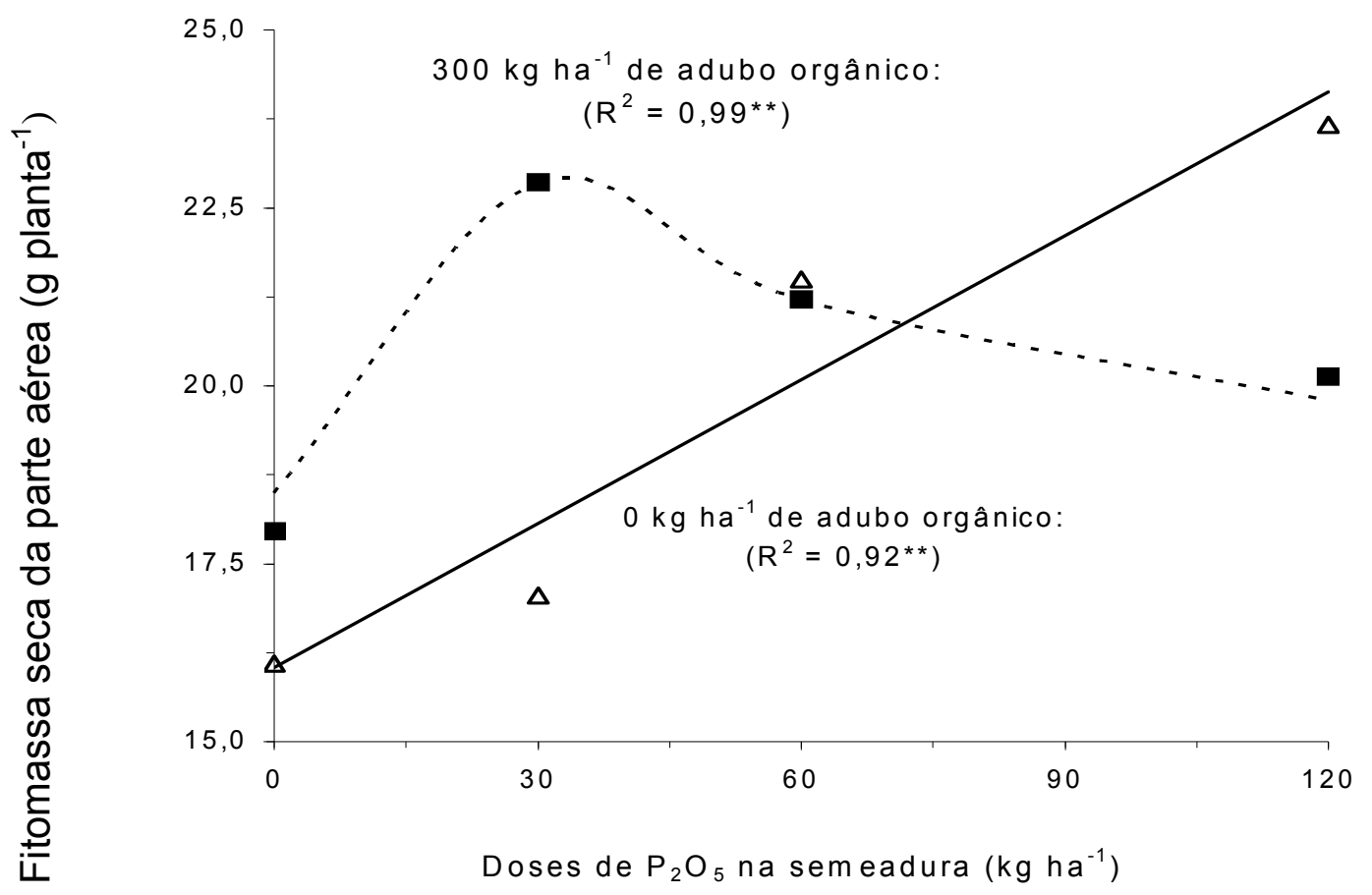

FIGURA 01 - Fitomassa seca da cultura do milho em função dos tratamentos aplicados. (घ) $300 \mathrm{Kg} \mathrm{ha}^{-1} \mathrm{e}$ $(\Delta) 0 \mathrm{Kg} \mathrm{ha}^{-1}$ de adubo orgânico

Os resultados de acúmulo de fósforo na parte aérea da cultura do milho encontram-se na Figura 2. O acúmulo de fósforo na parte aérea apresentou comportamento semelhante aos dados de fitomassa seca, indicando que o efeito no acúmulo de fósforo ocorreu devido a variação da produção de matéria seca. Embora o acúmulo de fósforo no milho tenha apresentado ajuste linear para acúmulo de fósforo na parte aérea com as doses crescentes de fósforo sem a 
aplicação de adubo orgânico, verificou-se que o maior acúmulo de fósforo ocorreu com a adição de $80 \mathrm{~kg} \mathrm{ha}^{-1}$ de $\mathrm{P}_{2} \mathrm{O}_{5}$ e presença do adubo orgânico. Portanto, o adubo orgânico também beneficiou o acúmulo de fósforo na parte aérea do milho.

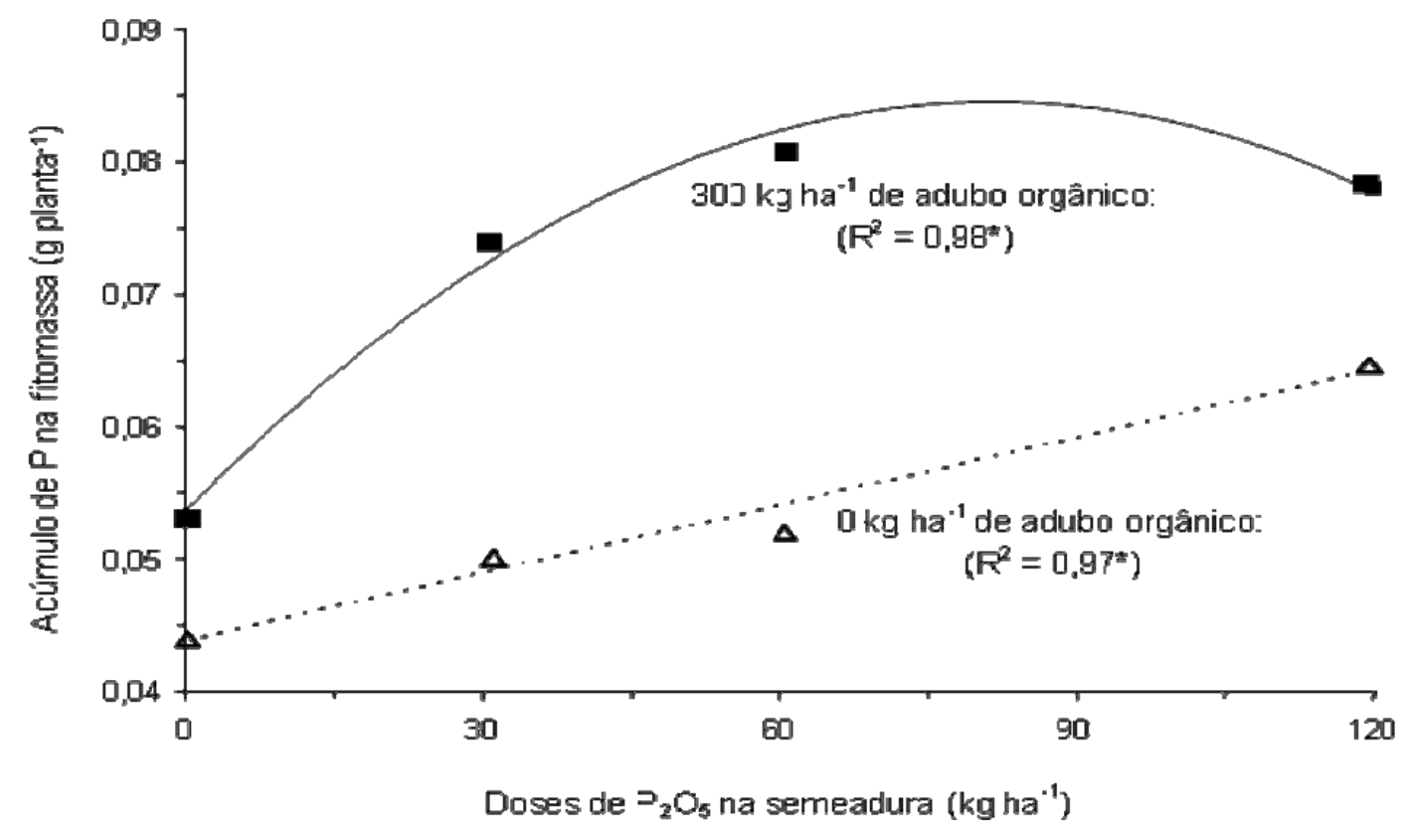

FIGURA 02 - Acúmulo de fósforo na fitomassa seca da cultura do milho submetido à adubação mineral e organomineral. (•) $300 \mathrm{Kg} \mathrm{ha}^{-1} \mathrm{e}(\Delta) 0 \mathrm{Kg} \mathrm{ha}^{-1}$ de adubo orgânico

Os resultados referentes ao teor de fósforo na parte aérea do milho encontram-se na Figura 3. Os teores de fósforo na parte aérea, diferente dos resultados de fitomassa seca e acúmulo de fósforo, não apresentaram diferenças estatisticamente significativas, independente da adubação utilizada. Os teores de fósforo na parte aérea do milho foram de 3,6 gramas de fósforo por quilograma de matéria seca na presença do adubo orgânico e de 2,7 gramas na ausência do adubo orgânico, revelando novamente que a utilização da matéria orgânica em conjunto com o adubo mineral resulta em diversos benefícios, uma vez que com um fornecimento adequado de matéria orgânica há um crescimento significativo na eficiência da adubação mineral.

Este resultado positivo é devido à matéria orgânica possuir importante papel na melhoria da fertilidade do solo e nas suas propriedades físicas. Para Alleoni e Beauclair (1995), a matéria orgânica eleva a capacidade de retenção de água, promove a redução da densidade aparente do solo e o aumento da porosidade total do solo, forma agregados capazes de reduzir a erosão e aumentar a capacidade de absorção do solo. Aumenta ainda a capacidade de troca catiônica, os teores de nitrogênio, fósforo e enxofre, a partir da decomposição e da mineralização da matéria orgânica, e promove a redução da fixação do fósforo pelos óxidos de ferro e alumínio, bloqueando os sítios de fixação com os radicais orgânicos. 


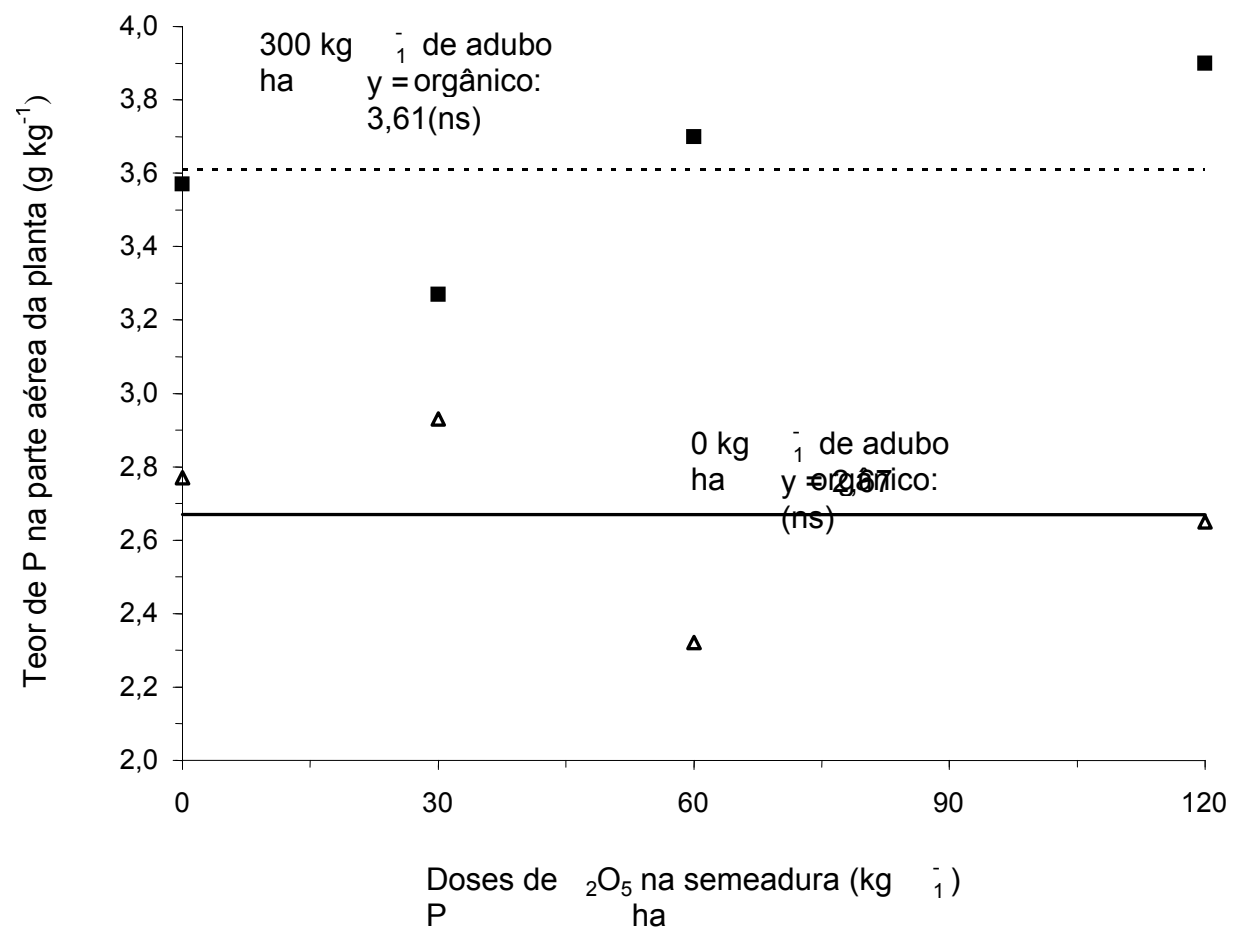

FIGURA 03 - Teor de fósforo na parte aérea das plantas de milho submetidas à adubação mineral e organomineral. (घ) $300 \mathrm{Kg} \mathrm{ha}^{-1} \mathrm{e}(\Delta) 0 \mathrm{Kg} \mathrm{ha}^{-1}$ de adubo orgânico

Para Bittencourt et al. (2006), o uso da matéria orgânica permite uma racionalização do adubo mineral, pois promove um aumento da capacidade de troca catiônica, evitando perdas por lixiviação e ajudando na liberação dos nutrientes à planta, como neste caso, em que ocorreu maior absorção de fósforo, elevando o teor deste nutriente na parte aérea da planta. Da mesma forma, Santos et al. (2010) recomendam, para elevar a eficiência da adubação fosfatada, com a consequente redução das doses empregadas, utilizar um carregador orgânico para proteger o fósforo da fixação.

\section{CONCLUSÃO}

A utilização de matéria orgânica em conjunto com a adubação mineral é viável, podendo ser utilizada como estratégia para elevar a produtividade agrícola e reduzir os custos de adubação na cultura do milho.

\section{REFERÊNCIAS}

ALLEONI, L. R. F.; BEAUCLAIR, E. G. F. Canade-açúcar cultivada após milho e amendoim, com diferentes doses de adubo. Scientia Agricola, Piracicaba, v. 52, n. 3, p. 409-415, 1995. BITTENCOURT, V. C. et al. Torta de filtro enriquecida. Idea News, Ribeirão Preto, v. 6, n. 63, p. 2-6, 2006.

EMBRAPA. Empresa Brasileira de Pesquisa Agropecuária. Centro Nacional de Pesquisa de Solos. Sistema brasileiro de classificação de solos. Rio de Janeiro: Embrapa, 2006, 306p.

GARCIA, J. C. Efeitos da adubação orgânica, associada ou não a adubação química, calagem e fosfatagem, nos rendimentos agrícola e de aguardente teórica da cana-deaçúcar (Saccharum spp). 2005. 82 p. Tese (Doutorado) Universidade federal de Lavras UFLA. Lavras.

GUERRA, J. G. M. et al. Conteúdo de fósforo em amostras de solos. Pesquisa Agropecuária Brasileira, v. 31, p. 291-299, 1996.

KAMPRATH, E. J.; WATSON, M. E. Conventional soil and tissue tests for assessing the phosphorus status of soils. In: KHASAWNEH, F. E.; SAMPLE, E. C.; KAMPRATH, E. J. (eds.). The role of phosphorus in agriculture. Madison: American Society of Agronomy, 1980. p.433-469. 
LEE, R. B. Selectivity and kinetics of ion uptake by barley plants following nutrient deficieny.

Annals of Bottany, v. 50, p. 429-449, 1982.

LOPES, A. S. (Trad.). Manual internacional de fertilidade do solo. 2.ed. Piracicaba:

POTAFOS, 1988.

MAGALHÃES, J. V. Alterações na absorção e no metabolismo de nitrogênio em diferentes níveis de estresse de fósforo em plantas de milho (Zea mays L.). 1995. Tese (Mestrado). Universidade Federal de Viçosa. Viçosa.

MENGEL, K.; KIRKBY, E. A. Principles of plant nutrition. Bern: International Potash Institute, 1987. $687 \mathrm{p}$.

MEURER, E. J. Potássio. In: FERNANDES, M. S. Nutrição mineral de plantas. Viçosa, MG: SBCS, 2006. p. 281-298.

MILLER, M. H. Effects of nitrogen on phosphorus absorption by plants. In: CARSON, E. W. (Ed.). The plant root and its environment. Charlottesville: University Press of Virginia, 1974. p. 634-668.

NOVAIS, R. F. Efeito do tempo de incubação do fosfato de araxá em solos sobre o fósforo disponível. Revista Brasileira de Ciências do Solo, v. 4, p. 153-155,1980.

RAIJ, B. et al. Análise química para avaliação da fertilidade de solos tropicais. Campinas: Instituto Agronômico, 2001. 284 p.

RAIJ, B.; CANTARELLA, H. Milho para grãos e silagem. In: RAIJ, B. et al. (Ed.).

Recomendações de adubação e calagem para o Estado de São Paulo. 2.ed. Campinas: IAC, 1997. 285 p. (Boletim Técnico, 100).

RAIJ, B. et al. (Ed.). Recomendações de adubação e calagem para o Estado de São Paulo. 2.ed. Campinas: IAC, 1997. 285p. (Boletim Técnico, 100).

RUFTY, T. W. et al. Phosphate regulation of nitrate assimilation in soybean. Journal of Experimental Botany, v. 44, p. 879-891, 1993. http://dx.doi.org/10.1093/jxb/44.5.879

SANTOS, D. H. Adubação da cana-de-açúcar com torta de filtro enriquecida com fosfato solúvel. 2009. 35 p. Dissertação (Mestrado em Agronomia). Universidade do Oeste Paulista Unoeste. Presidente Prudente - SP.

SANTOS, D. H. et al. Produtividade de cana-deaçúcar sob adubação com torta de filtro enriquecida com fosfato solúvel. Pesquisa
Agropecuária Tropical, Goiânia, v. 40, n. 4, p. 454-461, 2010.

SANTOS, V. R. Crescimento e produção da cana-de-açúcar em diferentes fontes de fósforo. 2006. 104 p. Dissertação (Mestrado) Universidade Federal de Alagoas.

SCHJORRING, J. K. Nitrate and Rio Largo ammonium absorvation by plants growing at a sufficient or insufficient level of phosphorus in nutrient solution. In: LAMERS, H. (Ed.).

Fundamental ecological and agricultural aspects of nitrogen metabolism in higher plants. Dordrecht: Martinus Nijhoff, 1996. p. 5358.

SIQUEIRA, J. O.; MOREIRA, F. M. S. Biologia e bioquímica do solo. Lavras: Universidade Federal de Lavras, 2001. 291 p.

TIESSEN, H.; MOIR, J. O. Characterization of available $P$ by sequential extraction. In: CARTER, M. R. (ed.). Soil sampling and methods of analysis. Boca Raton: Lewis, 1993. p. 75-86.

TURNER, B. L.; MAHIEU, N.; CONDRON, L. M. The phosphorus composition of temperate pasture soils determined by $\mathrm{NaOH}$-EDTA extraction and solution ${ }^{31} \mathrm{P}$ NMR spectroscopy. Org. Geochem., v. 34, p. 1199-1210, 2003 http://dx.doi.org/10.1016/S01466380(03)00061-5.

VASCONCELLOS, C. A. Níveis, métodos de aplicação e fontes de fosfatos na produção de milho. Pesquisa Agropecuária Brasileira, Brasília, v. 21, p. 245-54, 1986.

WETZEL, M. Efeito da adubação em solos de cerrado sobre a qualidade da semente de milho. I. Fósforo. In: CONGRESSO BRASILEIRO DE SEMENTES.1., Curitiba,1979. Resumos... Curitiba, ABRATES, 1979. p. 23. 